\title{
The Influence of Chief Executive Officers' Regulatory Foci on Firms' Advertising, R\&D, and Corporate Social Responsibility: An Abstract
}

\author{
Saim Kashmiri, Prachi Gala, and Cameron Duncan Nicol
}

\begin{abstract}
This research examines the influence of CEOs' regulatory foci on their firms' strategic marketing behavior. The authors propose that CEOs' degree of promotion focus relative to prevention focus positively impacts their firms' likelihood of investing in intangible market assets (i.e., R\&D, Advertising, and CSR). However, the authors also propose a dark side of CEOs' promotion focus: a higher likelihood of firms getting involved in corporate social irresponsibility (CSiR). The impact of CEOs' regulatory foci on firms' strategic marketing behavior is proposed to be weaker for firms where the power of the marketing department is high. Findings based on observing a sample of 395 publicly listed US firms between 2006 and 2010 provide considerable support for the authors' hypotheses. These results highlight the link between executives' regulatory foci and strategic marketing behavior and underscore the positive and negative consequences associated with these foci.
\end{abstract}

References Available Upon Request

\author{
S. Kashmiri $(\bowtie) \cdot$ P. Gala \\ University of Mississippi, Oxford, MS, USA \\ e-mail: skashmiri@bus.olemiss.edu; pgala@bus.olemiss.edu \\ C.D. Nicol \\ Union University, Jackson, MS, USA \\ e-mail: dnicol@uu.edu
}

